\title{
Duplication of PTHLH causes osteochondroplasia with a combined brachydactyly type E/A1 phenotype with disturbed bone maturation and rhizomelia
}

\author{
Ricarda Flöttmann ${ }^{1}$, Anna Sowinska-Seidler ${ }^{2}$, Julie Lavie ${ }^{3}$, Jean-François Chateil ${ }^{4}$, Didier Lacombe ${ }^{3,5}$, \\ Stefan Mundlos ${ }^{1,6,7}$, Denise Horn ${ }^{1}$ and Malte Spielmann ${ }^{\star, 1,6,7}$
}

Parathyroid hormone-like hormone (PTHLH, MIM 168470) plays an important role in endochondral bone development and prevents chondrocytes from differentiating. Disease-causing variants and haploinsufficiency of PTHLH are known to cause brachydactyly type $\mathrm{E}$ and short stature. So far, three large duplications encompassing several genes including PTHLH associating with enchondromatas and acro-osteolysis have been described in the literature. Here, we report on a three-generation pedigree with short humerus, curved radius, and a specific type of severe brachydactyly with features of types $E$ and $A 1$ but without the enchondromatas and the acro-osteolysis. Microarray-based comparative genomic hybridization (array-CGH) revealed a 70-kb duplication on chromosome 12p11.22 encompassing only PTHLH. Our data extend the phenotypic spectrum associated with copy number variations of $P T H L H$, and this family is to our knowledge the first description harboring a microduplication encompassing only PTHLH.

European Journal of Human Genetics (2016) 24, 1132-1136; doi:10.1038/ejhg.2015.266; published online 6 January 2016

\section{INTRODUCTION}

Parathyroid hormone-like hormone (PTHLH, MIM 168470) plays an important role during endochondral bone formation. Deletions and loss-of-function variants in PTHLH cause brachydactyly type E (MIM 613382) with short stature and oligodontia. ${ }^{1,2}$ Disease-causing variants in its receptor PTHR1 are known to cause Eiken syndrome $(\text { MIM } 600002)^{3}$ with severely retarded ossification of epiphyses, pelvis, hands, and feet, Jansen metaphyseal chondrodysplasia (MIM 156400) ${ }^{4}$ that is caused by constitutively active heterozygous variants and characterized by generalized osteopenia, and lethal Blomstrand chondrodysplasia (BOCD, MIM 215045) $)^{5}$ that is caused by inactivating loss-of-function variants and characterized by severe defects in endochondral bone formation.

Here, we report on a family that presented with autosomal dominant inheritance of short humerus, curved radius, and brachydactyly. ${ }^{6}$ Initially, several candidate genes for brachydactyly type A1 (BDA1) including IHH and GDF5 were excluded via Sanger sequencing and a $105 \mathrm{~K}$ microarray-based comparative genomic hybridization (array-CGH) was normal. Therefore, no molecular diagnosis could be established at the time. ${ }^{6}$ To exclude smaller copy number variations we recently performed high-resolution array-CGH ( $1 \mathrm{~m}$ ) and identified a 70-kb duplication encompassing only PTHLH. Mouse studies show that overexpression of PTHLH in proliferating chondrocytes results in chondrodysplasia and delayed endochondral bone formation. ${ }^{7}$ So far, three larger duplications encompassing a total of 5 to 12 genes have been described at the PTHLH locus. All three duplications are associated with enchondromatas and acro-osteolysis that are absent in our family. Therefore, we propose that enchondromatas and acro-osteolysis reported in other patients with larger duplications at the PTHLH locus might be because of duplications of one of the other genes, whereas short humerus, curved radius, and a specific type of severe brachydactyly with features of types E and A1 is caused by duplication of PTHLH itself.

\section{MATERIALS AND METHODS}

Microarray-based comparative genomic hybridization All experiments were done with genomic DNA extracted from blood samples.

Array-CGH was carried out using a whole-genome $1 \mathrm{~m}$ oligonucleotide array (Agilent, Santa Clara, CA, USA). The $1 \mathrm{~m}$ arrays were analyzed by Feature Extraction v9.5.3.1 and CytoGenomics 2.7.8.0 (Agilent). Analysis settings: aberration algorithm: ADM-2; threshold: 6.0; window size: $0.2 \mathrm{Mb}$; filter: 5 probes, $\log 2$ ratio $=0.29$. Data were submitted to the DECIPHER database (http://decipher.sanger.ac.uk); accession number: $308811 .^{8}$

\section{Quantitative real-time PCR (qPCR)}

The qPCR was performed on ABI Prism 7500 Sequence Detection System (Carlsbad, CA, USA) in a total volume of $24 \mu \mathrm{l}$ in each well containing $12 \mu \mathrm{l}$ of SYBR-Green PCR Master Mix (ABI SYBR Green PCR Master Mix, Carlsbad, CA, USA), 20 ng of genomic DNA (10 $\mu \mathrm{l})$, and $2 \mu \mathrm{l}$ primers $(0.2 \mu \mathrm{mol}$ each). Samples were run in triplicate in separate tubes to permit the quantification of the target sequences normalized to albumin $(A L B)$. PCR conditions were according to the

${ }^{1}$ Institute for Medical Genetics and Human Genetics, Charité Universitätsmedizin Berlin, Berlin, Germany; ${ }^{2}$ Department of Medical Genetics, Poznan University of Medical Sciences, Poznan, Poland; ${ }^{3}$ Laboratoire Maladies Rares: Génétique et Métabolisme (MRGM), Université de Bordeaux, EA4576, Bordeaux, France; ${ }^{4}$ Department of Pediatric Radiology, CHU de Bordeaux, Université de Bordeaux, Bordeaux, France; ${ }^{5}$ Department of Medical Genetics, CHU de Bordeaux, Bordeaux, France; ${ }^{6}$ Max Planck Institute for Molecular Genetics, Berlin, Germany; ${ }^{7}$ Berlin-Brandenburg School for Regenerative Therapies (BSRT), Berlin, Germany

*Correspondence: Dr M Spielmann, Institut für Medizinische Genetik und Humangenetik, Charité Universitätsmedizin Berlin, Augustenburger Platz 1 , 13353 Berlin, Germany. Tel: +49 30 84131643; Fax: +49 30 84131385; E-mail: malte.spielmann@charite.de

Received 11 September 2015; revised 3 November 2015; accepted 15 November 2015; published online 6 January 2016 
manufacturer's protocol and consisted of an initial denaturation step of $95^{\circ} \mathrm{C}$ for $8 \mathrm{~min}$ followed by 40 cycles with denaturation at $95^{\circ} \mathrm{C}$ for $15 \mathrm{~s}$ and a combined annealing/elongation step at $60^{\circ} \mathrm{C}$ for $1 \mathrm{~min}$. By using calibrator samples of normal control genomic DNA the gene copy number was estimated based on the ddCt method. In addition, we performed an identification of the individuals' genders calculating the coagulation factor VIII (F8, Xq28) relative to the two-copy-control $A L B$ to assure its reliability. Primer sequences are $12 \mathrm{p} \_\mathrm{A}$ ( $5^{\prime}$-TGTT ACCATATGCAGCCGAG-3') as control, 12p_B (5'-GCTTGAAGCAG GAGAAAGGA-3' $)$, 12p_C (5'-TGTGGGTCCCATTCTACACA-3'), 12p_D (5'-ACTTGGGTGTGGATGTGTGA-3') for the duplication, and 12p_E (5'-AGCAACTCAGGAACTGCACA-3') as another control.

\section{Fluorescence in situ hybridization (FISH)}

The array-CGH result was confirmed by FISH using BAC probes (RP11-86O17, RP11-204E9) located within the deletion on chromosome 12p11.22.

\section{RESULTS}

\section{Clinical report}

Patient 1: detailed clinical and radiological findings of the patient and the family were published by Lacombe et al. ${ }^{6}$ During the third trimester of pregnancy shortness of humeri $(<3$ centile) was diagnosed by ultrasound and confirmed by skeletal study on $3 \mathrm{D}$ CT. The patient was born at 39 weeks of gestation by cesarean section (weight $3.000 \mathrm{~g}$, height $50 \mathrm{~cm}$, OFC $35.5 \mathrm{~cm}$ ). Short arms, radial deviation of hands, and brachydactyly were present at birth. Growth was normal at age 19 months and he had a moderate limitation of prono-supination. Cognitive development was normal.

Family members: the mother underwent surgery for osteotomy of the tibia at age 16 years because of genu valgum. Her height was $154 \mathrm{~cm}(-1.75 \mathrm{SD})$, weight $51 \mathrm{~kg}(-1 \mathrm{SD})$, and OFC $56 \mathrm{~cm}(+1 \mathrm{SD})$. She had short arms, a radial angulation of forearms, limitation of prono-supination, and brachydactyly of hands and feet. Hearing was normal.

One maternal uncle, the maternal grandmother, and a great-uncle showed the same chondrodysplasia with brachydactyly, short humerus, and radial incurvation of the forearms (see pedigree, Figure 1). Mental status was normal in all family members. Hearing loss was present in the grandmother and the uncle. No other associated phenotypes like abnormalities of parathyroid glands or abnormal levels of thyroid and parathyroid hormones were observed in the family.

\section{Radiological findings}

Patient 1: radiographs of the hand and arm at different ages show extremely hypoplastic and irregular shaped metacarpals, abnormally shaped proximal phalanges with distal tapering, hypoplastic middle phalanges, especially the second and the fifth are affected, and thin distal phalanges. The carpal bones and the radius epiphysis are still not ossified at the age of 19 months. In addition, the radiograph at 19 months of age revealed large and premature appearing epiphyses of the metacarpals II to V, large pseudoepiphyses at their distal ends, and premature appearing phalangeal epiphyses.

Furthermore, radiographs revealed short humerus, mild bowing of radius, and short ulna with an accessory ossification center at its proximal end (Figure 2b).

Radiographs of pelvis and the lower limbs at 19 months demonstrated lack of ossification of the pubic bones, short femoral necks, and metaphyseal irregularities on femurs. Cervical lordosis with basilar impression was present.

Sister of patient 1: radiographs of the hands of the affected sister at age 8 months reveals delayed carpal ossification as well as radial and ulnar epiphyseal maturation, extremely short and misshaped metacarpals with premature appearing epiphyses and presence of large pseudoepiphyses at their proximal ends, mild distal tapering of proximal phalanges with epiphyses that appear too early, hypoplasia and abnormal shape of middle phalanges with large and premature appearing epiphyses of digits II to IV, and hypoplasia of distal phalanges II to IV.

Mother: Radiographs during infancy showed short and broad humerus, abnormal incurvation of radius with short ulna and relative hypoplasia of the lateral condyle. At the time of examination, radiographs showed short and broad I, III, and IV metacarpals, short II, IV, and V middle phalanges, slight tapering of the distal phalanx of digit IV, abnormal metacarpophalangeal joint in digit V, and short I, $\mathrm{IV}$, and $\mathrm{V}$ metatarsals. Ulna was rather short, with radial luxation. Vertebrae were normal.

\section{Molecular cytogenetics}

In a patient with BDA1, short humerus, and associated skeletal features, array-CGH was performed and revealed a 70-kb duplication encompassing PTHLH on chromosome 12 (HGVS: hg19 chr12:g.

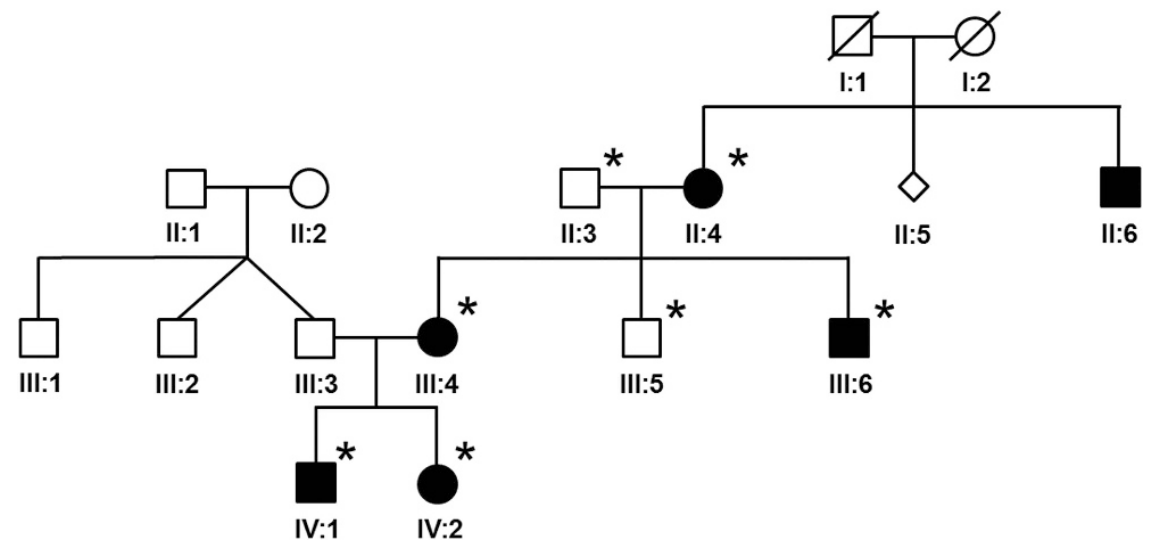

Figure 1 Pedigree of the family. Affected family members are indicated in black. The asterisk indicates that DNA samples were available and qPCR was done. The $70 \mathrm{~kb}$ duplication encompassing PTHLH was detected in all affected family members and was absent in the maternal grandfather and the maternal uncle. 

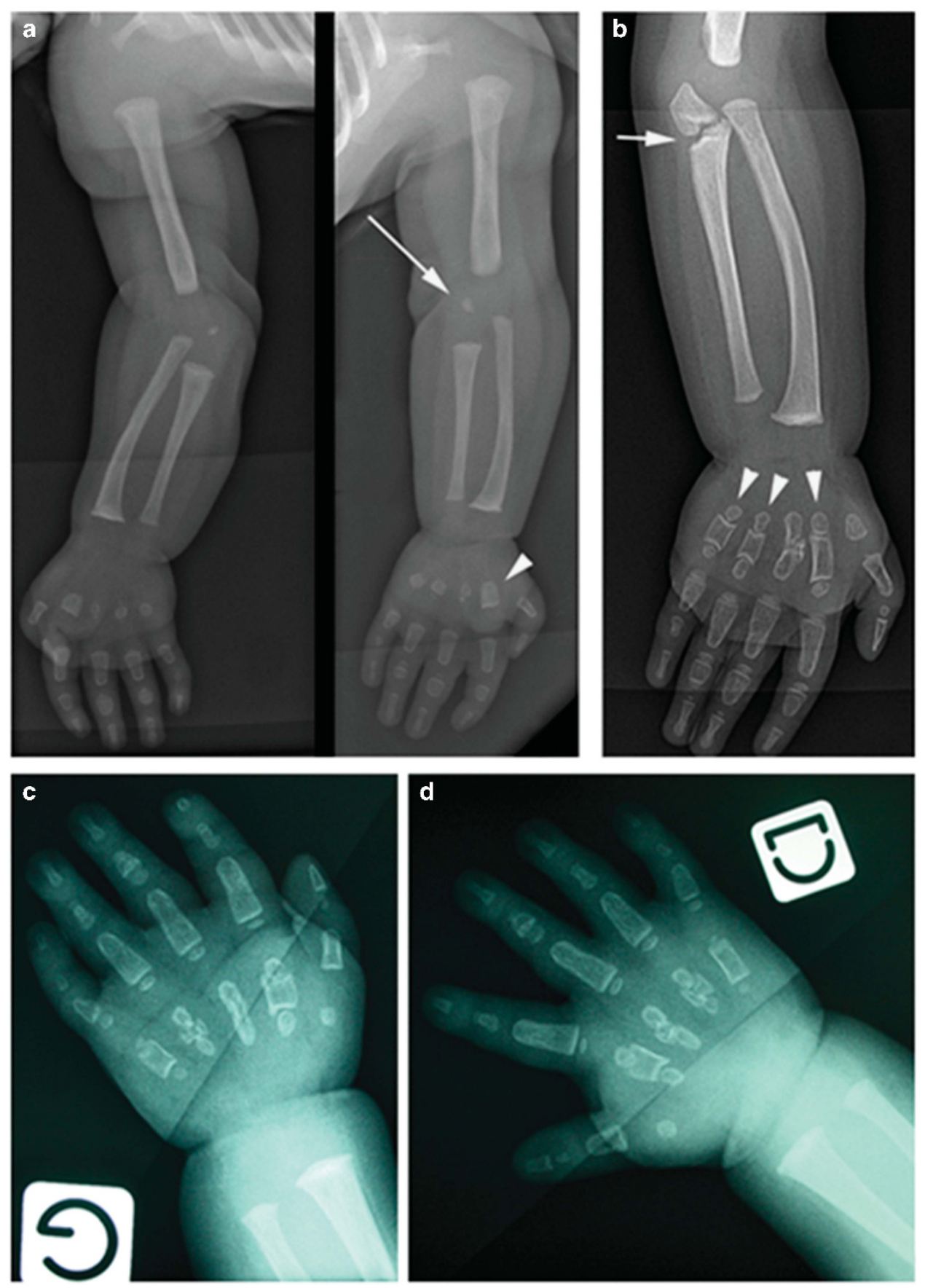

Figure 2 Radiographs of patient 1 and sister. (a) At birth: note shortened humerus, slight bowing of radius, and short ulna with an accessory ossification center at the proximal part. Hands: short and irregular metacarpals, short and broad second to fifth middle phalanges. (b) Forearm and hand at 19 months: aspect of 'pseudarthrosis' at the proximal third of the ulna (arrow), short metacarpals with accessory ossification center (arrowheads), and shortness of middle phalanges, tapering of distal phalanges. Abnormal epiphyseal maturation of metacarpals and phalanges, delayed ossification of carpal bones. (c, d) Hands of the similarly affected sister of patient 1 at age 8 months. Note marked hypoplasia of misshaped metacarpals with accessory ossifications centers at their proximal ends, the shortness of the middle phalanges, disturbed pattern of carpal and epiphyseal maturation with nonossified carpal bones, as well as radial and ulnar epiphyses and - in contrast - advanced and abnormal maturation of metacarpal and phalangeal epiphyses.

(28079052_28082255)_(28152554-28163179)dup; ISCN: $\operatorname{arr}[\mathrm{hg} 19]$ 12p11.22 (28 $082255-28152554) \times 3$ (minimal positions)). (Figure 3, Supplementary Figure 1). The result was confirmed by qPCR and five other family members were tested consequently (Supplementary Figure 2). To exclude an insertional translocation FISH was performed using a BAC probe (RP11-299E2)
(Supplementary Figure 3). The FISH result revealed that the duplicated fragment was not inserted at a different locus. According to Newman et al, ${ }^{9} 83 \%$ of all duplications are oriented in tandem. The duplication was found in all affected individuals and was absent in the nonaffected maternal uncle and maternal grandfather (Supplementary Figure 2). For a summary of the results see the pedigree in Figure 1. 


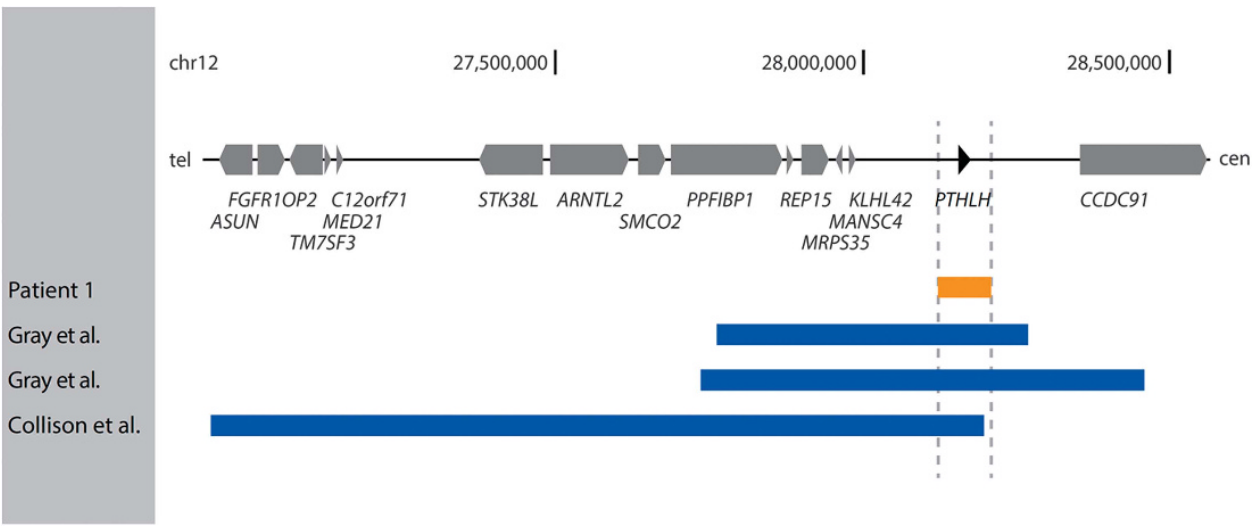

Figure 3 Genomic locus of the duplicated region on chromosome 12p11.22. Centromeric is right, telomeric is left. Genes and their direction of transcription are indicated by gray boxes/arrows. A broken vertical line indicates the minimal critical region. The duplications reported here are shown below the gene symbols, indicated by orange (our patient) and blue (patients reported in the literature) bars.

Table 1 Phenotypic characteristics of our patients and the patients described by Collinson et al ${ }^{11}$ and Gray et al ${ }^{10}$

\begin{tabular}{|c|c|c|c|c|c|c|}
\hline & Our patient 1 & Mother of patient 1 & Sister of patient 1 & Collinson et al ${ }^{11}$ & Case 1 Gray et al ${ }^{10}$ & Case 3 Gray et al ${ }^{10}$ \\
\hline \multicolumn{7}{|l|}{ Clinical features } \\
\hline Height & & Short stature & & Short stature & & Short stature \\
\hline Limbs & $\begin{array}{l}\text { Short arms } \\
\text { Radial deviation of hands } \\
\text { Brachydactyly }\end{array}$ & $\begin{array}{l}\text { Short arms } \\
\text { Genu valgum } \\
\text { Radial angulation of forearm } \\
\text { Limitation prono-supination } \\
\text { Brachydactyly }\end{array}$ & & $\begin{array}{l}\text { Mesomelic shortened limbs } \\
\text { and symmetrical bony expan- } \\
\text { sions of wrists, elbows, } \\
\text { knees, and ankles }\end{array}$ & $\begin{array}{l}\text { Shortened distal } \\
\text { phalanges, clubbed } \\
\text { great toes } \\
\text { Bowing of left tibia and left } \\
\text { radius }\end{array}$ & $\begin{array}{l}\text { Asymmetric limb } \\
\text { deformities } \\
\text { Leg asymmetry }\end{array}$ \\
\hline Other & & & & $\begin{array}{l}\text { Symmetrical } \\
\text { enchondromatosis }\end{array}$ & $\begin{array}{l}\text { Coarse facial features, } \\
\text { osteoporosis }\end{array}$ & \\
\hline \multicolumn{7}{|c|}{ Radiological findings } \\
\hline Humerus & Short humerus & Short humerus & & Short long bones & & Radiolucencies \\
\hline Radius and ulna & $\begin{array}{l}\text { Bowing of radius } \\
\text { Short ulna pseudarthrosis } \\
\text { in proximal third of the ulna }\end{array}$ & $\begin{array}{l}\text { incurvation of radius } \\
\text { Short ulna }\end{array}$ & $\begin{array}{l}\text { Delayed radial and ulnar } \\
\text { epiphyseal maturation }\end{array}$ & $\begin{array}{l}\text { Symmetrical metaphyseal } \\
\text { lesions }\end{array}$ & $\begin{array}{l}\text { Bowing of radius, } \\
\text { metadiaphyseal } \\
\text { irregularity in ulna }\end{array}$ & $\begin{array}{l}\text { Mild distal phalangeal } \\
\text { shortening (BDB) } \\
\text { Radiolucencies }\end{array}$ \\
\hline Hands & $\begin{array}{l}\text { Short and misshaped } \\
\text { metacarpals and II-IV } \\
\text { middle phalanges } \\
\text { Prox. accessory ossification } \\
\text { centers at metacarpals } \\
\text { Premature epiphyseal } \\
\text { development of metacarpals } \\
\text { and phalanges } \\
\text { Delayed carpal ossification }\end{array}$ & $\begin{array}{l}\text { Short and broad metacarpals } \\
\text { I, III, and IV (metatarsal I, IV, V) } \\
\text { short middle phalanges (II, IV, V) } \\
\text { Abnormal metacarpophalangeal } \\
\text { joint in digit V }\end{array}$ & $\begin{array}{l}\text { Short and misshaped } \\
\text { metacarpals and middle } \\
\text { phalanges II to IV with } \\
\text { premature appearing } \\
\text { epiphyses } \\
\text { Distal tapering of } \\
\text { proximal phalanges, and } \\
\text { hypoplasia of distal } \\
\text { phalanges II to IV delayed } \\
\text { carpal ossification }\end{array}$ & $\begin{array}{l}\text { Brachydactyly type E with } \\
\text { cone-shaped epiphyses }\end{array}$ & $\begin{array}{l}\text { Progressive acroosteolysis } \\
\text { of terminal phalanges }\end{array}$ & $\begin{array}{l}\text { Acroosteolysis of } \\
\text { distal phalanges (I, II) }\end{array}$ \\
\hline Feet & Short metatarsals & & & $\begin{array}{l}\text { Brachydactyly type E with } \\
\text { cone-shaped epiphyses }\end{array}$ & & \\
\hline Other & $\begin{array}{l}\text { Cervical lordosis with basilar } \\
\text { impression } \\
\text { Delayed ossification of } \\
\text { pubic bones }\end{array}$ & & & & $\begin{array}{l}\text { Basilar invagination of } \\
\text { the skull } \\
\text { Arnold Chiari malformation } \\
\text { Coarse facial features } \\
\text { Significant osteoporosis } \\
\text { Osteolysis of femoral head } \\
\text { and acetabulum }\end{array}$ & $\begin{array}{l}\text { Irregularity of rib } \\
\text { length and form }\end{array}$ \\
\hline
\end{tabular}

The $70 \mathrm{~kb}$ duplication was detected in all affected family members, the index, his sister, the mother, one maternal uncle, and the maternal grandmother. It was absent in the unaffected maternal grandfather and the unaffected maternal uncle. The duplication encompassed PTHLH as the only protein-coding gene.

\section{DISCUSSION}

In this study we identified a 70-kb microduplication on chromosome 12p11.22 encompassing PTHLH in four individuals of a family presenting with short humerus, curved radius, and a specific pattern of hand bone abnormalities, namely extremely short and misshaped 
metacarpals and middle phalanges with disturbed epiphyseal maturation. Whereas the metacarpal and phalangeal epiphyseal maturation is accelerated and disturbed, the carpal bone maturation as well as the pubic bone maturation is delayed in infancy.

PTHLH is a key player in endochondral bone development and deletions and disease-causing single-nucleotide variants in PTHLH are known to cause brachydactyly type E. ${ }^{1}$ So far, three large duplications encompassing PTHLH and 5 to 12 other genes have been described in the literature. ${ }^{10,11}$ The duplications were associated with mesomelic limb shortening and enchondromatosis or acro-osteolysis. Collinson et $a l^{11}$ described a patient with mesomelic limb shortening and symmetrical enchondromatosis carrying a large de novo duplication encompassing 12 genes, among them PTHLH. Two other families presented with acro-osteolysis, bowed long bones, and metaphyseal lesions that radiographically resembled enchondromata. Array-CGH revealed a 502-kb and a $851-\mathrm{kb}$ duplication respectively. Both duplications encompassed PTHLH and five or six other genes respectively. ${ }^{10}$ None of the genes that are encompassed in the larger duplications have been shown to play a role in skeletal development. A comparison of the phenotypic characteristics of our patients and the patients described by Gray et $a l^{10}$ and Collinson et $a l^{11}$ is given in Table 1. The DECIPHER database lists 12 overlapping duplications. All of them are considerably larger (starting from $3.9 \mathrm{Mb}){ }^{8}$

PTHLH is known to regulate the balance between chondrocyte proliferation and the onset of differentiation during endochondral bone development. PTHLH is regulated by Indian Hedgehog (IHH) and operates via its receptor parathyroid hormone 1 receptor (PTHR1, MIM 168468). ${ }^{12}$ Together, IHH and PTHLH form a feedback loop that regulates the onset of hypertrophic differentiation and thus endochondral bone development. ${ }^{13}$ Inactivation of Pthlh in the mouse results in a lethal short-limbed chondrodysplasia. ${ }^{14}$ Overexpression of Pthlh in proliferating chondrocytes in mice results in profound delay of maturation. Weir et $a l^{\vec{p}}$ report that overexpression of Pthlh in chondrocytes using the mouse type II collagen promoter induces a novel form of chondrodysplasia characterized by short-limbed dwarfism and a delay in endochondral ossification. Based on a delay in chondrocyte differentiation the mice are born with a cartilaginous endochondral skeleton but at the age of 7 weeks, the delays in chondrocyte differentiation and ossification of the mice have largely been corrected, leaving foreshortened and misshapen bones. ${ }^{7}$

Our patients, as well as the above-mentioned cases carrying lager duplications, share features such as short humerus, curved radius, and brachydactyly. However, in our family multiple enchondromatas or acro-osteolysis were absent. Given the fact that overexpression of Pthlh in mice causes a distinct chondrodysplasia with a short-limbed dwarfism very similar to our patients, it is likely that the upper limb shortening, the mildly bowed bones, the specific type of severe brachydactyly, and the disturbed bone maturation are caused by duplication of PTHLH. The enchondromatas and the acro-osteolysis, characteristic for the larger 12p11.22 duplications, are most likely because of a duplication of one of the other genes. A potential candidate is Homo sapiens kelch-like family member 42 (KLHL42) as it was shown to be expressed in mouse embryonic limbs. ${ }^{15}$ Other members like the kelch-like (KLHL) gene family have been shown to be involved in renal $\mathrm{Na}+$ and $\mathrm{Cl}-$ homeostasis. ${ }^{16}$

It is also possible that the different duplications have effects on long-range regulation of $P T H L H$ and thereby result in variable PTHLH expression levels causing the phenotypic differences. The differential effects of PTHLH in the hands and carpals of the patients remain difficult to explain. The generalized dwarfism of the mouse is most likely because of the higher dosage of Pthlh (fourfold overexpression).

Our data extend the phenotypic spectrum associated with copy number variations of $P T H L H$, and this family is to our knowledge the first description harboring a microduplication encompassing only PTHLH.

\section{CONFLICT OF INTEREST}

The authors declare no conflict of interest.

\section{ACKNOWLEDGEMENTS}

We thank the families for their collaboration and contribution to this project as well as Fabienne Pritsch and Antje Gerlach for their technical work.

1 Klopocki E, Hennig BP, Dathe $\mathrm{K}$ et al: Deletion and point mutations of PTHLH cause brachydactyly type E. Am J Hum Genet 2010; 86: 434-439.

2 Mundlos S: The brachydactylies: a molecular disease family. Clin Genet 2009; 76 : $123-136$.

3 Duchatelet S, Ostergaard E, Cortes D, Lemainque A, Julier C: Recessive mutations in PTHR1 cause contrasting skeletal dysplasias in Eiken and Blomstrand syndromes. Hum Mol Genet 2005; 14: 1-5.

4 Schipani E, Kruse K, Juppner H: A constitutively active mutant PTH-PTHrP receptor in Jansen-type metaphyseal chondrodysplasia. Science 1995; 268: 98-100.

5 Zhang $P$, Jobert AS, Couvineau A, Silve C: A homozygous inactivating mutation in the parathyroid hormone/parathyroid hormone-related peptide receptor causing Blomstrand chondrodysplasia. J Clin Endocrinol Metabol 1998; 83: 3365-3368.

6 Lacombe D, Delrue MA, Rooryck C et al: Brachydactyly type A1 with short humerus and associated skeletal features. Am J Med Genet A 2010; 152A: 3016-3021.

7 Weir EC, Philbrick WM, Amling M, Neff LA, Baron R, Broadus AE: Targeted overexpression of parathyroid hormone-related peptide in chondrocytes causes chondrodysplasia and delayed endochondral bone formation. Proc Natl Acad Sci USA 1996; 93: 10240-10245.

8 Firth HV, Richards SM, Bevan AP et al: DECIPHER: Database of Chromosomal Imbalance and Phenotype in Humans Using Ensembl Resources. Am J Hum Genet 2009; 84: 524-533.

9 Newman S, Hermetz KE, Weckselblatt B, Rudd MK: Next-generation sequencing of duplication CNVs reveals that most are tandem and some create fusion genes at breakpoints. Am J Hum Genet 2015; 96: 208-220.

10 Gray MJ, van Kogelenberg M, Beddow R et al: A new acro-osteolysis syndrome caused by duplications including PTHLH. J Hum Genet 2014; 59: 484-487.

11 Collinson M, Leonard SJ, Charlton J et al: Symmetrical enchondromatosis is associated with duplication of $12 \mathrm{p} 11.23$ to $12 \mathrm{p} 11.22$ including PTHLH. Am J Med Genet A 2010; 152A: 3124-3128

12 Kronenberg HM: PTHrP and skeletal development. Ann NY Acad Sci 2006; 1068 : $1-13$.

13 Vortkamp A, Lee K, Lanske B, Segre GV, Kronenberg HM, Tabin CJ: Regulation of rate of cartilage differentiation by Indian hedgehog and PTH-related protein. Science 1996; 273: 613-622.

14 Karaplis AC, Luz A, Glowacki J et al: Lethal skeletal dysplasia from targeted disruption of the parathyroid hormone-related peptide gene. Genes Dev 1994; 8: 277-289.

15 Cotney J, Leng J, Oh S et al: Chromatin state signatures associated with tissue-specific gene expression and enhancer activity in the embryonic limb. Genome Res 2012; 22: 1069-1080.

16 Dhanoa BS, Cogliati T, Satish AG, Bruford EA, Friedman JS: Update on the Kelch-like (KLHL) gene family. Hum Genomics 2013; 7: 13.

Supplementary Information accompanies this paper on European Journal of Human Genetics website (http://www.nature.com/ejhg) 